\title{
De BeERS NEAR COLORLESS-TO-BLUE EXPERIMENTAL GEM-QUALITY SYNTHETIC DIAMONDS
}

\author{
By Marie-Line T. Rooney, C. M. Wellboum, James E. Shigley, Emmanuel Fritsch, and Ilene Reinitz
}

\begin{abstract}
Examination of five small boron-doped synthetic diamonds, grown by De Beers researchers for experimental purposes, reveals some diagnostic features not reported in previous studies of gem-quality synthetic diamonds. The presence of internal growth sectors that are blue, yellow, or near colorless has produced faceup colors in three faceted stones that vary from near colorless to bluish-greenish gray to blue. Because they look so different from previously reported De Beers synthetic diamonds, such faceted synthetics could go unrecognized without careful gemological testing should they ever become commercially available.
\end{abstract}

Previous articles on gem-quality synthetic diamonds have reported the visible zoning of certain features such as color, ultraviolet luminescence, and graining, and their importance as identification criteria for this material (see Shigley et al., 1986, 1987, 1992). Recently, we examined two small crystals $(0.12$ and $0.20 \mathrm{ct})$ and three faceted De Beers synthetic diamonds $\mid 0.05$ to $0.07 \mathrm{ct}$ ) that are interesting examples of a kind of internal color zoning that produces a variable overall color appearance (figure 1). Several polished plates of

\section{ABOUT THE AUTHORS}

Mrs. Rooney and Dr. Welbourn are research scientists at the De Beers Diamond Trading Company (DTC) Research Centre in Maidenhead, United Kingdom. Dr. Shigley is director of research, Dr. Fritsch is manager of research, and Dr. Reinitz is a research scientist, at the Gemological Institute of America, Santa Monica and New York.

Acknowledgments: The authors thank Dr. R. J. Caveney, director of research at the De Beers Industrial Diamond Division (Pty.) Ltd. Diamond Research Laboratory (DRL), Johannesburg, South Africa, for the loan to GlA of the boron-doped synthetic diamonds. Vesna Cvetkovic of the DRL grew the synthetic diamonds discussed in this article. Karin Hurwit of the GIA Gem Trade Laboratory provided the color and clarity descriotions of the three faceted stones. Mike Moon and Sam Muhimeister of GIA Research prepared the visible and infrared absorption spectra.

Gems \& Gemology, Vol. 29, No. 1, pp. 38-45

(C) 1993 Gemological Institute of America this same kind of synthetic diamond were described by two of us (MLTR and CMW) in recent reports on the development of internal growth sectors in synthetic diamonds (see Burns et al., 1990; Rooney, 1992).

Single-crystal synthetic diamonds normally are yellow, which results from the incorporation of nitrogen atoms from the surrounding environment into the diamond (by substitution as isolated atoms for carbon atoms) at the time of growth. The presence of nitrogen as an impurity reportedly aids in the growth of larger, higher-quality crystals. In the case of the samples studied here, the yellow color was reduced by using a nitrogen getter (an element that acts to bond with the nitrogen outside of the growing diamond crystal, and thereby reduces its incorporation within the crystall in the synthesis capsule. Also, varying amounts of boron-known to be responsible for the blue color in many natural and synthetic diamondswere added to the synthesis capsule in the growth runs.

During rapid growth under laboratory conditions, synthetic diamond crystals can develop octahedral, cube, dodecahedral, and trapezohedral external crystal faces and corresponding internal growth sectors. As the different internal sectors grow, they tend to incorporate certain impurities in different amounts. Thus, the resulting synthetic diamond crystal is partially inhomogeneous in chemical composition. In particular, nitrogen and boron are incorporated to a varying 
TABLE 1. Luminescence of De Beers boron-doped experimental synthetic diamonds.

\begin{tabular}{|c|c|c|c|}
\hline Luminescence behavior & Sample 1 & Sample 2 & Sample 3 \\
\hline \multicolumn{4}{|c|}{ Long-wave U.V. fluorescence } \\
\hline Color & Orange & Slightly yellowish orange & Orange \\
\hline Intensity & Weak & Moderate & Very weak \\
\hline Appearance & Chalky, turbid & Chalky, turbid & \\
\hline Distribution & $\begin{array}{l}\text { Uneven; narrow, inert } \\
\text { cross-shaped area seen } \\
\text { under crown facets }\end{array}$ & $\begin{array}{l}\text { Uneven; narrow, inert } \\
\text { straight band seen } \\
\text { across crown facets }\end{array}$ & Uneven \\
\hline \multicolumn{4}{|c|}{ Long-wave U.V. phosphorescence } \\
\hline Color & Orange & Yellowish orange & Inert \\
\hline Intensity & Weak & Strong & \\
\hline Duration & $1-5$ minutes & $1-5$ minutes & \\
\hline \multicolumn{4}{|c|}{ Short-wave U.V. fluorescence } \\
\hline Color & Slightly greenish yellow & $\begin{array}{l}\text { Slightly greenish yellow } \\
\text { (plus minor orange) }\end{array}$ & Slightly greenish yellow \\
\hline Intensity & Strong & Strong & Strong \\
\hline Appearance & Chalky, turbid & Chalky, turbid & Chalky, turbid \\
\hline Distribution & Uneven; narrow, inert & Uneven; narrow, inert & Uneven; small, angular, \\
\hline & $\begin{array}{l}\text { cross-shaped area seen } \\
\text { under crown facets }\end{array}$ & $\begin{array}{l}\text { straight band seen } \\
\text { across crown facets }\end{array}$ & inert areas \\
\hline \multicolumn{4}{|c|}{ Short-wave U.V. phosphorescence } \\
\hline Color & Greenish yellow & Yellow & Yellow \\
\hline Intensity & Very strong & Very strong & Very strong \\
\hline Duration & $1-5$ minutes & $1-5$ minutes & $1-5$ minutes \\
\hline \multicolumn{4}{|l|}{ Cathodoluminescence } \\
\hline Color & Yellow & Yellow & Yellow \\
\hline Intensity & Strong & Strong & Strong \\
\hline Distribution & Uneven & Uneven & Uneven \\
\hline
\end{tabular}

testing equipment as well as other laboratory instrumentation. The former included a gemological microscope, a long-wave $(366 \mathrm{~nm})$ and short-wave $(254 \mathrm{~nm})$ ultraviolet lamp unit, a Beck prism spectroscope, a DISCAN digital-scanning diffraction-grating spectroscope, and a GIA GEM electrical conductometer with sharp probes to allow testing of specific locations on a sample. Our examination was hindered by the small

Figure 2. The intense cathodoluminescence of the three faceted synthetic diamonds is characteristic of other synthetic diamonds we have studied. As can be seen here, this luminescence is unevenly distributed. A dark, cross-shaped area that does not luminesce is visible in two of the stones. Photo by Maha DeMaggio.

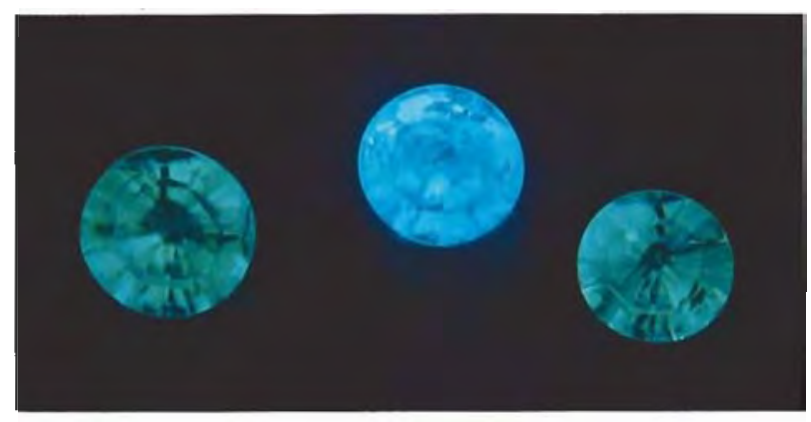

size of the faceted stones (diameter less than $3 \mathrm{~mm}$ ) which made observation and photography of some of the gemological features difficult. A Pye-Unicam 8800 spectrophotometer was used to record absorption spectra at liquid-nitrogen temperature over the range 250-850 nm. A Nicolet 60SX Fourier-Transform infrared spectrometer was used to record infrared spectra over the range $400-16,000 \mathrm{~cm}^{-1}$. Observations of cathodoluminescence were made using a Nuclide ELM-2B luminoscope.

In the study of crystal morphology, a Huber 302 two-circle optical-reflection goniometer was used to measure interfacial angles on several crystals. A Cambridge Instruments Stereoscan 360 scanning electron microscope (SEM) was used to produce micrographs of the small crystals.

\section{OBSERVATIONS}

Overall Faceup Color. The variation in appearance from near-colorless to blue among the faceted samples results from differences in the relative size, arrangement, and color of their internal growth sectors (see figure 1 ). When the blue and yellow sectors are relatively equal in volume and lighter in color, the overall faceup appearance of a faceted stone is more "grayish" or "greenish" (such as sample 1). Both crystals appear blue. 


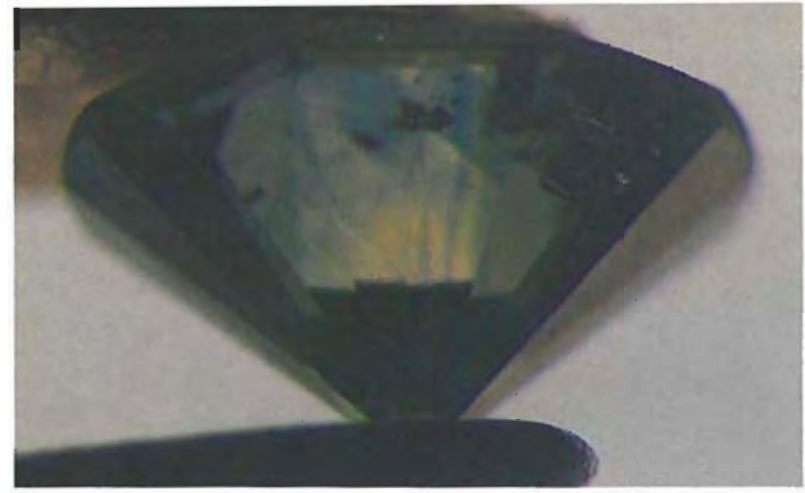

Figure 3. The arrangement of darker blue, lighter yellow, and near-colorless internal growth sectors in sample 2 is seen here with diffused light. The small opaque areas represent metallic flux inclusions. The arrangement of internal growth sectors is less obvious in the other two faceted stones. Photomicrograph by John I. Koivula.

Luminescence. In contrast to behavior reported previously (Shigley et al., 1986, 1987, 1992), the three faceted synthetic diamonds described here luminesced to both long- and short-wave ultraviolet radiation /see table 1). However, the long-wave U.V. fluorescence-weak to moderate-was weaker in intensity than the short-wave U.V. response. Most U.V.-luminescing natural diamonds react more strongly to long-wave U.V. In all five study samples, the luminescence to U.V. radiation was uneven, and sometimes clearly zoned, as has been the case with other synthetic diamonds. When viewed faceup, all three faceted stones exhibited narrow linear, angular, or cross-shaped areas that did not fluoresce, surrounded by larger areas that fluoresced brightly. In most cases, when the lamp was turned off, the stones exhibited very persistent, very strong, yellow (to short-wave U.V.) or orange (to long-wave U.V.) phosphorescence lasting from one to five minutes.

The three faceted stones displayed cathodoluminescence when they were exposed to an electron beam. This luminescence was quite intense, andas has been noted in previous studies of synthetic diamonds (Woods and Lang, 1975; Shigley et al., 1987; Ponahlo, 1992)-it was also zoned in color and intensity (see table 1). To the unaided eye, the luminescence appears yellow, but photography recorded more blue than yellow for one sample (figure 2). Although difficult to see in figure 2, the uneven pattern of cathodoluminescence-bright areas separated by narrow inert areas, both of which can be observed with magnification - duplicates the uneven pattern of ultraviolet luminescence in these samples. Cathodoluminescence provides an additional means of distinguishing synthetic from natural diamonds, because it reveals the differing patterns of intemal growth sectors characteristic of the two (see Shigley et al., 1987; Burns et al., 1990; Ponahlo, 1992). This test is particularly useful where no other diagnostic properties are visible.

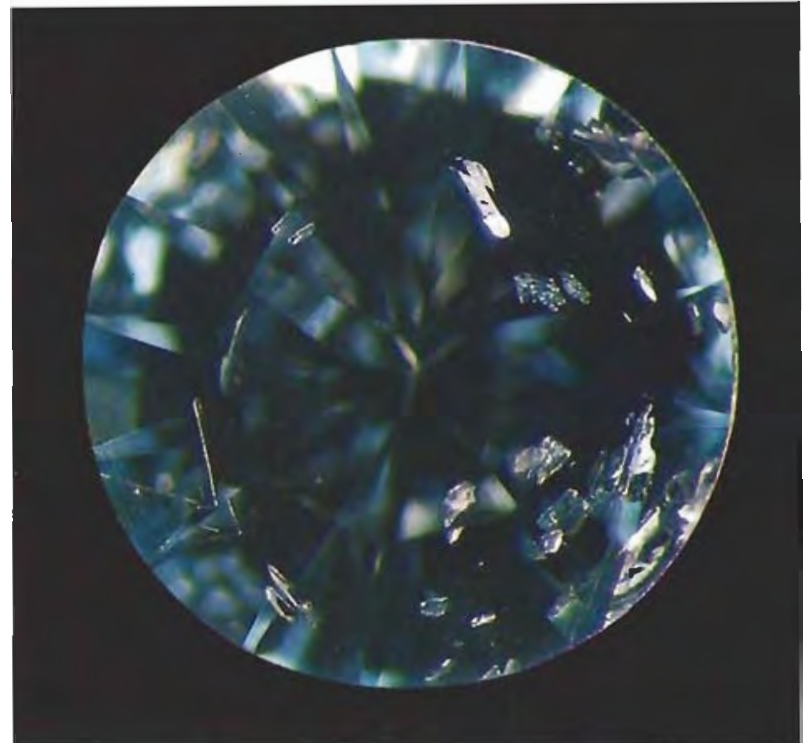

Figure 4. Numerous metallic flux inclusions can be seen through the crown facets of sample 2. Photomicrograph by John I. Koivula; reflected light.

Microscopy. When viewed with a gemological microscope, the three faceted stones revealed several interesting features. In diffused transmitted light, all three were seen to consist of darker to lighter blue, light yellow, and near-colorless internal growth sectors in varying arrangements (see, e.g., figure 3 ). The blue sectors display a more distinct shape, and appear as wedge- or parallelogram-shaped, lath-like zones bounded by sharp edges and having angular corners. In sample 1 , near-colorless to yellow funnel-shaped areas occur between these blue sectors. The outlines of the yellow and near-colorless growth sectors are not as distinct. Thus, the shape of the blue sectors is more readily apparent. This is also the case for the two crystals, where the blue sectors were observed to lie beneath the cube crystal faces.

All five samples contain inclusions, but these are most abundant in sample 2 (see figure 4). Various numbers of both large and smaller "pinpoint" flux (i.e., metal solvent) inclusions were observed in the three faceted stones. The larger inclusions have a shiny, metallic appearance, and in some cases seem to be oriented parallel both to one another and to the octahedral faces of the original crystal. Similar inclusions in other gem-quality synthetic diamonds have previously been reported (Shigley et al., 1986, 1987).

When viewed between crossed polarizing filters, the five samples exhibited anomalous birefringence ("strain") with weak (first-order) interference colors. Near the larger flux inclusions, the strain formed a more radial pattern with slightly stronger first-order interference colors (see figure 5). The overall weakness of this birefringence is typical of that observed in other synthetic diamonds, and it differs in intensity and pattern from the more intense anomalous birefringence typically seen in natural diamonds. 


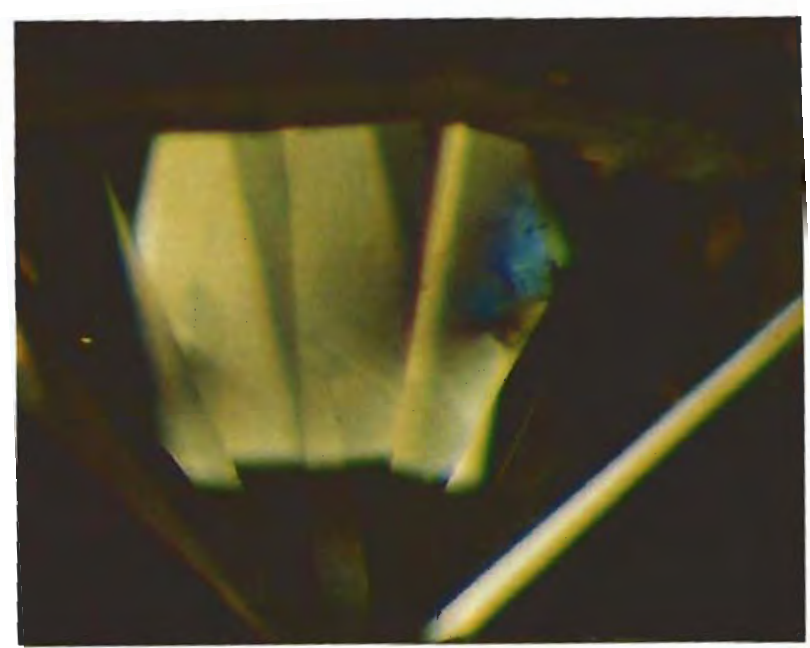

Figure 5. A pattern of weak anomalous birefringence ("strain") was seen in sample 3 when it was viewed between crossed polarizing filters. The small area of bhe birefringence is an area of greater strain surrounding a metallic flux inchasion. Photomicrograph by lohn Koivula; magnified 10x.

We saw little distinct graining in any of the three faceted stones, and none in the two crystals, although in some instances, the relatively sharp edges of the darker blue internal growth sectors were marked by visible graining. These synthetic diamonds lack the pattern of internal graining observed in yellow synthetic diamonds (Shigley et al., 1986, 1987), possibly because they contain less nitrogen.

Electrical Conductivity. The three faceted samples exhibited a range of conductive behavior: Sample 1 was electrically conductive (with instrument readings similar to those for natural type Ib diamonds), sample 2 proved to be conductive only in certain areas of the crown and pavilion facets, and sample 3 was not conductive. Both crystals were conductive, with various readings depending on where on their surfaces they were tested.

Spectroscopy. We did not observe any sharp absorption bands in the optical absorption spectra of the five samples with a Beck desk-model spectroscope. Because of the small size of these samples and the fact that three were faceted, it was impossible to record spectral curves with the spectrophotometer that would represent individual blue, yellow, or colorless growth sectors. The spectrophotometer traces for all three faceted samples showed increasing absorption toward the ultraviolet (figure 6). The spectra of samples 1 and 2 also showed weak to moderate increasing absorption toward the infrared, especially in the dark blue faceted stone (sample 2). There is a weak, broad absorption feature at about $700 \mathrm{~nm}$ in the spectra of samples 1 and

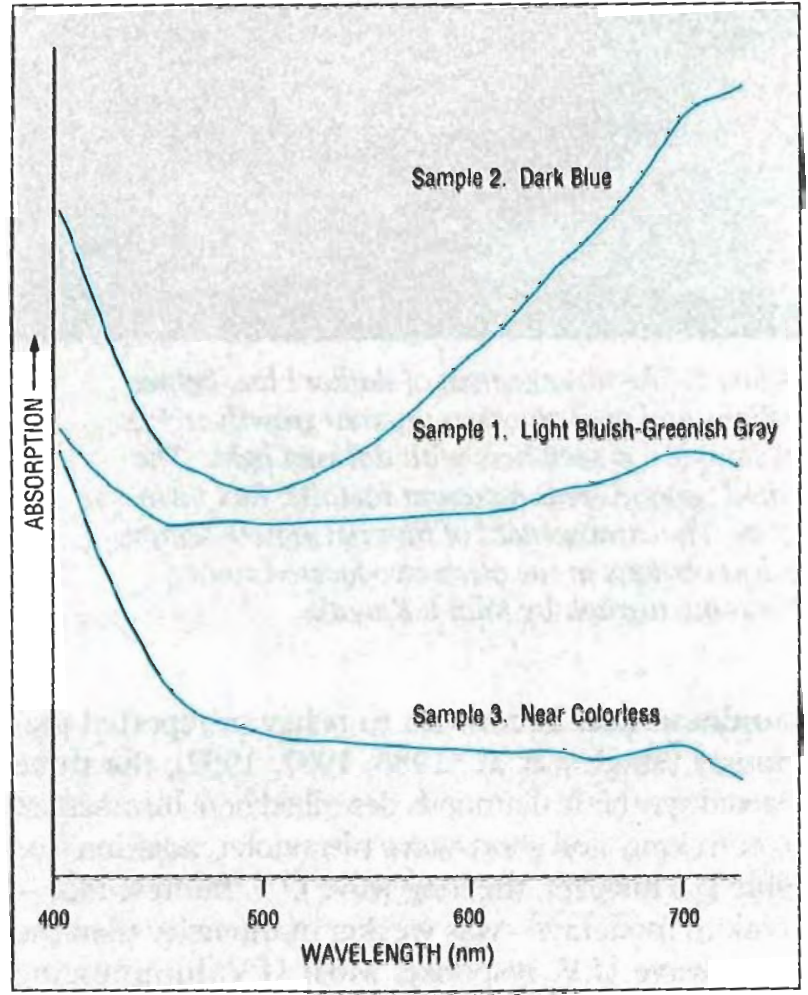

Figure 6. The visible spectra of all three faceted synthetic diamonds, recorded at liquid-nitrogen temperature, show increasing absorption toward the ultraviolet. For samples 1 and 2, weak or moderate increasing absorption is also evident toward the infrared. In contrast to the other two samples, the stronger increasing absorption at the longwavelength end of its spectrum gives rise to the darker blue color of sample 2 .

3 , which we have seen in many spectra of both natural and synthetic diamonds, but we are uncertain of its interpretation. In comparison, natural colorless or yellow type Ia diamonds often have sharp absorption bands due to the N3 color center (the Cape lines). Neither natural nor synthetic blue type IIb and yellow type $\mathrm{Ib}$ diamonds show any sharp bands in the visible-range spectrum.

The diamond type of a particular stone can be identified by its infrared spectrum (see, e.g., Fritsch and Scarratt, 1992, pp. 38-39). The infrared spectra of the three faceted stones (figure 7) suggest that sample 1 is a mixed type IIb plus Ila diamond, while sample 2 is a type IIb. This is consistent with their observed electrical conductivity. Sample 3 is a type Ila plus $\Pi \mathrm{Ib}$. Because the three faceted samples are so small, the infrared spectrum of each represents contributions from various growth sectors throughout the entire sample. Given the size of the yellow growth sectors in each of the three samples, together with the unfavorable measurement geometry for recording spectra 
from small faceted stones, it is not surprising that we do not see the 1344 and the $1130 \mathrm{~cm}^{-1}$ infrared features in these spectra that distinguish type Ib diamond. However, infrared spectra of individual yellow growth sectors recorded by Rooney $(1992$, p. 18, figure 3 ) in a polished section of one of these boron-doped synthetic diamonds indicates that these growth sectors are type Ib diamond. Thus, it is likely that all synthetic diamonds of this kind are actually a mixed type IIa plus IIb plus $\mathrm{Ib}$.

Crystal Form and the Nature of Internal Growth Sectors. Previous articles (e.g., Shigley et al., 1986, 1987, 1992; Burns et al., 1990) have described the basic growth shape of a synthetic diamond crystal as that of a cuboctahedron, which can be modified by the presence of minor dodecahedral and trapezohedral faces. The presence of true cube $\{100\}$, dodecahedral $\{110\}$, and trapezohedral $\{113\}$ faces is characteristic of synthetic diamond crystals; genuine crystallographic faces with these Miller indices are not found on natural diamond crystals. * The presence of these faces on the surface of a crystal is generally accompanied by distinctive internal growth sectors also not seen in natural stones. Gemological features associated with this kind of more complicated growth and the presence of one or more growth sectors-e.g., zoning of color and luminescence-are, therefore, important for the identification of synthetic diamonds.

A number of these boron-doped synthetic diamonds, in uncut form, have been studied at the DTC Research Centre. Some were found to have a new kind (not previously seen on natural or synthetic diamonds) of trapezohedral growth face in addition to $\{113\}$. Figure 8 shows an SEM micrograph and corresponding labeled line drawing of one of these crystals. Note in this figure that there are additional trapezohedral faces lying between the $\{113\}$ faces and the top (001) face. In a recent report on these borondoped synthetic diamonds, Rooney (1992) demonstrated (by measurement of the angles between crystal faces) that these new faces are $\{115\}$ faces. Subsequently, these faces were reported on a Sumitomo synthetic diamond by Shigley et al. (1992). Again, the presence

\footnotetext{
"The generalized symbol /hkll refers to the Miller indices, a nomenclature system that crystallographers use to designate crystallographic planes (or faces) and to calculate the angles between them. When these Miller indices are surrounded by braces [f, they represent a crystal form, which is a group of crystal faces that all have the same position with respect to the symmetry elements of the crystal. For example, all crystal faces on a cube with Miller indices (100), (010), and (001), can be described by the one symbol $\{100\}$
}

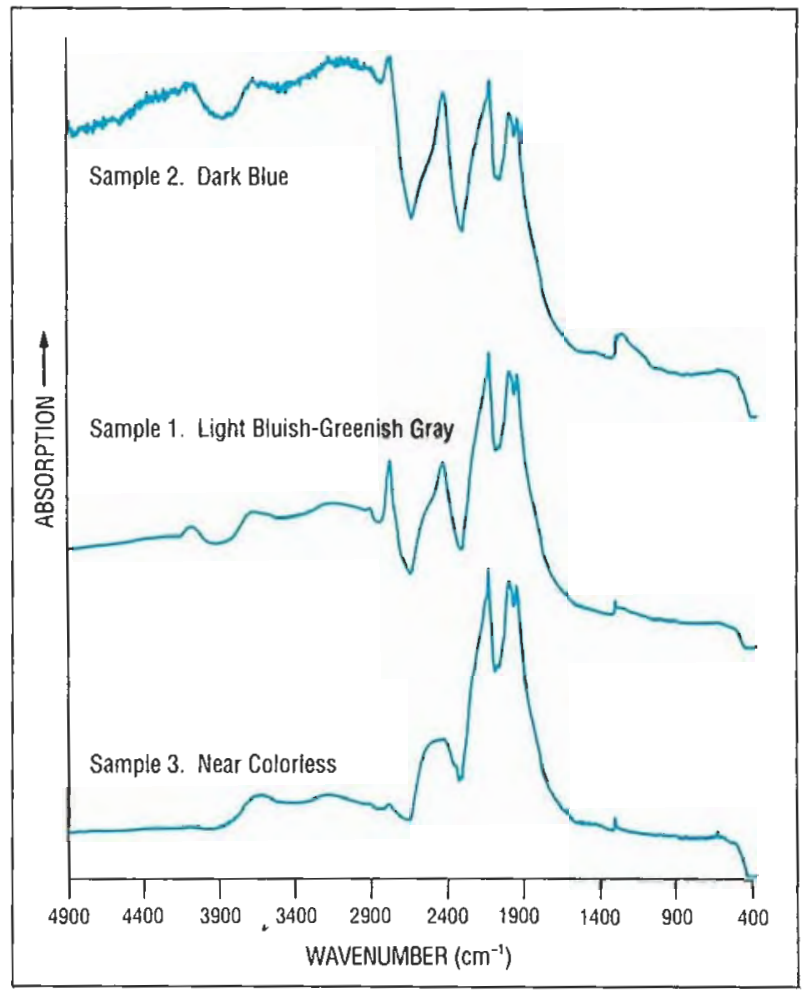

Figure 7. Because the internal growth zones are so small, it was impossible to record infrared spectra from individual zones; thus, these curves represent composite spectra for the three faceted synthetic diamond samples. According to these spectra, sample 2 is a type 11 b diamond, sample 1 is a mixed type IIb+Ila diamond, and sample 3 is a mixed type Ila+IIb diamond. The type Ib component related to the yellow growth sectors could not be resolved.

of nonoctahedral crystal faces-which might be present on unpolished portions of a faceted synthetic diamond-is further evidence of the difference between natural and laboratory growth environments for diamonds.

Rooney's (1992) description of two other borondoped synthetic diamonds, prepared as thin polished plates, confirmed the presence of internal $\{115\}$ growth sectors corresponding to external faces on this kind of synthetic diamond. Optical micrographs of these two samples (with corresponding line drawings of their growth sector arrangement) are shown in figures 9 and 10, respectively. The samples were polished parallel to the $(110)$ dodecahedral plane so as to expose individual growth sectors. These two samples show clearly how measured differences in impurity content lead to visible differences in color and other gernological properties. 


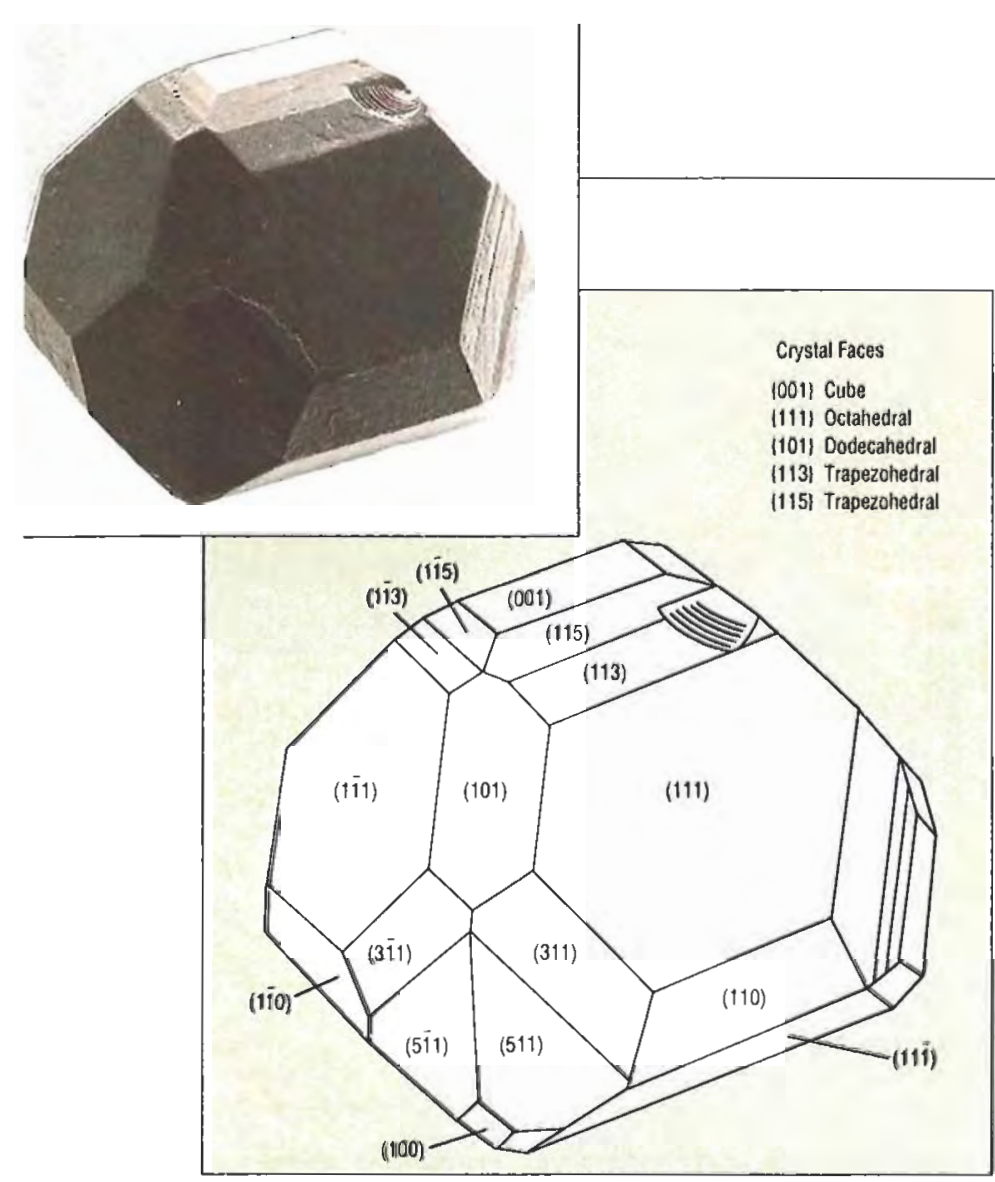

Figure 8. This low-magnificalion scanning electron micrograph and line drawing of a small borondoped synthetic diamond crystal show the arrangement of crystal faces. Note the additional (115) trapezohedral faces lying between the (113) faces and the top (001) face.

Cube and octahedral growth faces are always present on synthetic diamonds. The presence of the minor growth forms (dodecahedral and trapezohedral) depends on the solvent/catalyst chemistry. When present, their location, number, and relative size tend to be rather haphazard, presumably reflecting the details of the local growth conditions within the synthesis capsule. This seems to be especially true of these particular boron-doped synthetic diamonds, where there can be very large differences in the relative development of sectors of similar type.

\section{DISCUSSION}

In some respects, the gemological properties of these three faceted stones are similar to those of other synthetic diamonds: internal color zoning, strong shortwave U.V. fluorescence and cathodoluminescence that are unevenly distributed, metallic flux inclusions, and weak anomalous birefringence ("strain"). In contrast to other synthetic diamonds studied by GIA researchers, however, these five samples exhibit some, albeit weak, long-wave U.V. fluorescence. However, the short-wave response was more intense than the long-wave response, which differs significantly from

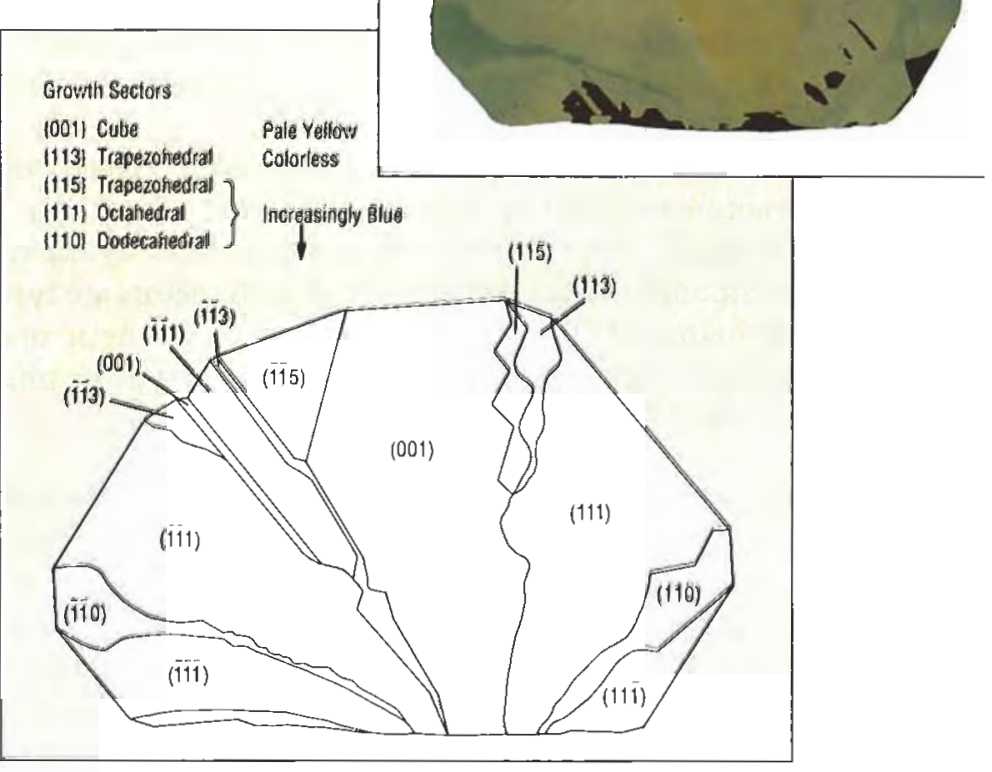

Figure 9. A transmission optical photomicrograph and growth-sector line drawing of a 0.075-ct borondoped synthetic diamond in the form of a polished plate $(0.55 \mathrm{~mm}$ thick, $3.9 \mathrm{~mm}$ wide). The 1001 ) growth sector is pale yellow. The (113) sectors are essentially colorless. The remaining sector types are all blue, with the intensity of color increasing in the order (115), |111), (110). Infrared measurements (Rooney, 1992) indicate that the yellow color in the 1001/ sectors resulted from its being type Ib (nitrogen concentration of about $11 \mathrm{ppm}$ ). For the blue type $I I b$ regions, the concentration of uncompensated boron was approximately 0.55 ppm for (115), 1.1 ppm for (111), and 2.2 ppm for (110) sectors. Photo by C. M. Welbourn.

the stronger long-wave fluorescence typical of natural diamonds that fluoresce to U.V. radiation. In addition, the three stones lacked the prominent graining noted in yellow synthetic diamonds (see Shigley et al., 1986, 1987).

The most interesting aspect of these synthetic diamonds is their mixed IIa, IIb, and Ib character, which has never been reported for natural diamond crystals (although it was noted in a large Sumitomo synthetic diamond crystal; Shigley et al., 1992). The differing incorporation of boron and nitrogen in the internal growth sectors causes the variation in color from one sector to another. Because the degree to which impurities are incorporated can also vary from one crystal to another, this kind of synthetic diamond could vary greatly in color from near-colorless to gray (or green) to blue and to yellow (and thus also in some properties, such as electrical conductivity and luminescence). Crystals in which the color sectors are of 


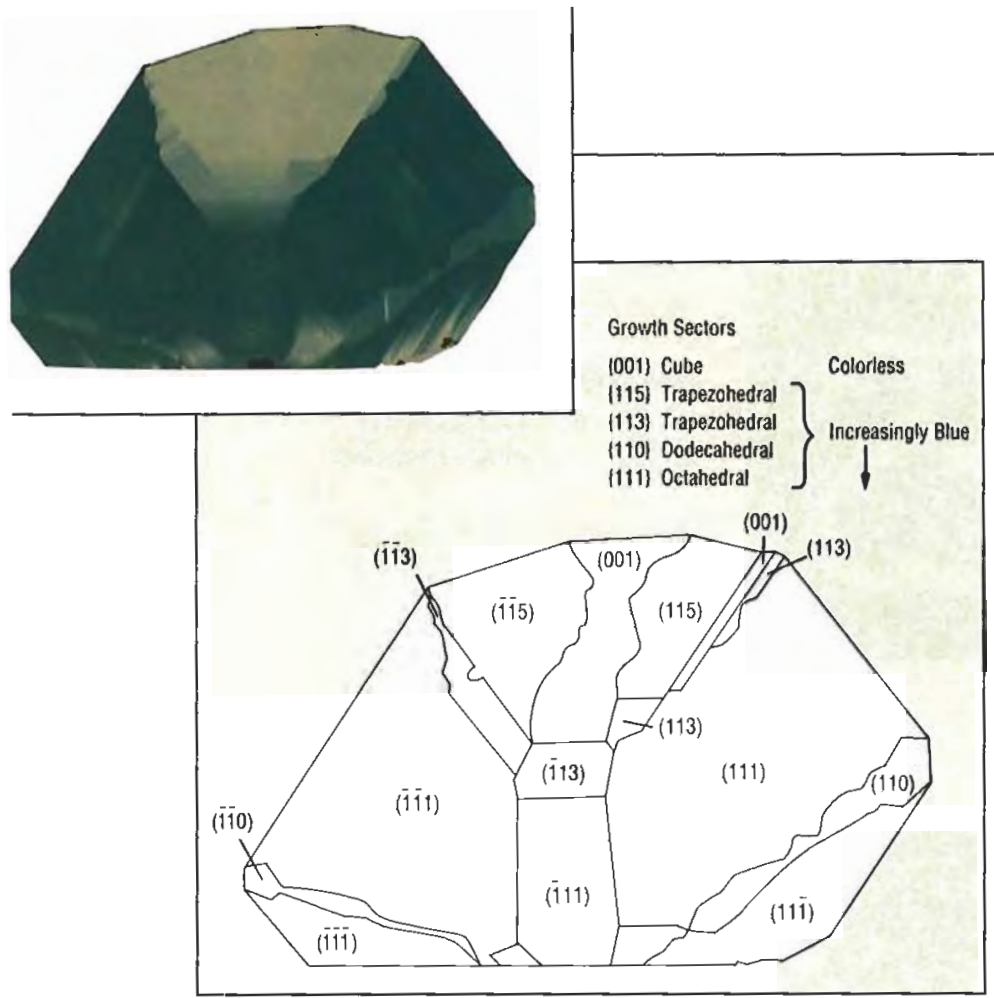

Figure 10. The 0.014-ct synthetic diamond (shown here in the form of a polished plate $0.19 \mathrm{~mm}$ thick and $4.2 \mathrm{~mm}$ wide) in this transmission optical photomicrograph and growth-sector line drawing was doped with 14 times as much boron as the one shown in figure 9. Infrared spectra (Rooney, 1992) indicpte no nitrogen but 0.08 ppm uncompensated boron in the $\{001\}$ sectors. Similar boron concentrations in other sectors are: $\{111\}-40 \mathrm{ppm}$, (110\}-25 ppm, \{113\}-9 ppm, and $\{115\}-4 \mathrm{ppm}$. Photo by C. M. Welbourn.

relatively equal proportions could appear grayish or slightly greenish, and thus may not look like other synthetic diamonds to the unaided eye. However, exam-

ination with a gemological microscope should quickly reveal the presence of the kind of color zoning illustrated in figure 3 , which has never been encountered in natural diamond crystals.

\section{CONCLUSION}

Examination of three small faceted De Beers synthetic diamonds and two small crystals reveals that they are a mixed type. The presence of different proportions of three distinct-blue, yellow, and near-colorless-growth sectors affects the faceup color of each finished stone. Because of this combination of colors, these synthetic diamonds look more like natural diamonds than most other synthetic diamonds reported in the gemological literature. The presence of nonoctahedral faces unique to synthetic diamonds is another feature by which they can be distinguished from their natural counterparts. Furthermore, since it is much more economical to grow small rather than large synthetic diamonds, it is possible that small ( 0.10 ct or less) faceted synthetic diamonds will appear first in the jewelry industry. Nonetheless, documentation of the gemological properties of these De Beers synthetic diamonds-e.g., metal inclusions, generally strong zoned short-wave U.V. fluorescence and phosphorescence, weak birefringence, and the color zoning itself-indicates that identification should be easy, since these properties do not correspond to those of any known natural diamonds. However, this could require that small near colorless-to-blue faceted diamonds that are suspect be gemologically tested-a practice that is not commonly followed now.

\section{REFERENCES}

Bundy F.P., Strong H.M., Wentorf R.H. Jr. (1973) Methods and mechanisms of synthetic diamond growth. Chemistry and Physics of Carbon, Vol. 10, pp. 213-263.

Bums R.C., Cvetkovic V., Dodge C.N., Evans D.J.F., Rooney M-L.T., Spear P.M., Welbourn C.M. (1990) Growth-sector dependence of optical features in large synthetic diamonds. Journal of Crystal Growth, Vol. 104, pp. 257-279.

Crowningshield R. (1971) General Electric's cuttable synthetic diamonds. Gems e) Gemology, Vol. 13, No. 10, pp. 302-314.

Fritsch E., Scarratt K. (1992) Natural-color nonconductive gray-toblue diamonds. Gems थ Gemology, Vol. 28, No. 1, pp. 35-42.

Koivula J.I., Fryer C.W. \{1984\} Identifying gem-quality synthetic diamonds: An update. Gems ev Gemology, Vol. 20, No. 3, pp. 146-158.

Nassau K., Nassau J. (1978) The history and present status of synthetic diamond: Part II. Lapidary lournal, Vol. 32, No. 2, pp. $490-508$.

Ponahlo J. (1992) Cathodoluminescence (CL) and CL spectra of De Beers' experimental synthetic diamonds. Journal of Gemmology, Vol. 23, No. 1, pp. 3-17.

Rooney M-L.T. (1992) \{115\} Growth in boron-doped synthetic dia- monds. Journal of Crystal Growth, Vol. 116, pp. 15-21.

Shigley J.E., Fritsch E., Stockton C.M., Koivula J.I., Fryer C.W., Kane R.E. (1986) The gemological properties of the Sumitomo gem-quality synthetic yellow diamonds. Gems a Gemology, Vol. 22, No. 4, pp. 192-208.

Shigley J.E., Fritsch E., Stockton C.M., Koivula J.I., Fryer C.W., Kane R.E., Hargett D.R., Welch C.W. (1987) Gemological properties of the De Beers gem-quality synthetic diamonds. Gems ex Gemology, Vol. 23, No. 4, pp. 187-206.

Shigley J.E., Fritsch E., Reinitz I., Moon M. (1992) An update on Sumitomo gem-quality synthetic diamonds. Gems et Gemology, Vol. 28, No. 2, pp. I16-122.

Sunagawa I. (1984) Morphology of natural and synthetic diamond crystals. In I. Sunagawa, Ed., Materials Science of the Earth's Interior, Terra Scientific Publishing Co., Tokyo, pp. 303-330.

Welbourn C.M., Rooney M-L.T., Evans D.J.F. (1989) A study of diamonds of cube and cube-related shape from the Jwaneng mine. Journal of Crystal Growth, Vol. 94, pp. 229-252.

Woods G.S., Lang A.R. (1975) Cathodoluminescence, optical absorption, and X-ray topographic studies of synthetic diamonds. Journal of Crystal Growth, Vol. 28, pp. 2I5-226. 